\title{
The phocein homologue SmMOB3 is essential for vegetative cell fusion and sexual development in the filamentous ascomycete Sordaria macrospora
}

\author{
Yasmine Bernhards $\cdot$ Stefanie Pöggeler
}

Received: 23 August 2010/Revised: 6 December 2010/Accepted: 27 December 2010/Published online: 13 January 2011

(C) The Author(s) 2011. This article is published with open access at Springerlink.com

\begin{abstract}
Members of the striatin family and their highly conserved interacting protein phocein/Mob3 are key components in the regulation of cell differentiation in multicellular eukaryotes. The striatin homologue PRO11 of the filamentous ascomycete Sordaria macrospora has a crucial role in fruiting body development. Here, we functionally characterized the phocein/Mob3 orthologue SmMOB3 of $S$. macrospora. We isolated the gene and showed that both, proll and Smmob3 are expressed during early and late developmental stages. Deletion of Smmob3 resulted in a sexually sterile strain, similar to the previously characterized pro1 1 mutant. Fusion assays revealed that $\Delta$ Smmob3 was unable to undergo self-fusion and fusion with the pro11 strain. The essential function of the SmMOB3 $\mathrm{N}$-terminus containing the conserved mob domain was demonstrated by complementation analysis of the sterile $S$. macrospora $\Delta \mathrm{Smmob3}$ strain. Downregulation of either pro11 in $\Delta \mathrm{Smmob3}$, or Smmob3 in pro11 mutants by means of RNA interference (RNAi) resulted in synthetic sexual defects, demonstrating for the first time the
\end{abstract}

Communicated by J. Heitman.

Electronic supplementary material The online version of this article (doi:10.1007/s00294-010-0333-z) contains supplementary material, which is available to authorized users.

Y. Bernhards $\cdot$ S. Pöggeler

Institute of Microbiology and Genetics,

Department of Genetics of Eukaryotic Microorganisms,

Georg-August University, Grisebachstr. 8,

37077 Göttingen, Germany

\section{S. Pöggeler $(\bowtie)$}

Institute of Microbiology and Genetics,

Georg-August University, Grisebachstr. 8,

37077 Göttingen, Germany

e-mail: spoegge@gwdg.de importance of a putative PRO11/SmMOB3 complex in fruiting body development.

Keywords Phocein - Hyphal fusion - Fruiting body development $\cdot$ Sordaria macrospora

\section{Introduction}

Efficient cell signaling and accurate control of signal transduction pathways are indispensable for cell differentiation. With their small genomes and established classic as well as molecular genetic tools, filamentous fungi are used as model organisms for genetically deciphering the basic mechanisms underlying eukaryotic cell differentiation. Sordaria macrospora is a filamentous ascomycete and an important model organism in developmental biology. During its sexual life cycle, $S$. macrospora forms multicellular fruiting bodies, a genetically controlled differentiation process that is used to characterize developmental genes (Kück et al. 2009).

Proteins of the striatin family act as platforms for the assembly of eukaryotic signaling pathways conserved from filamentous fungi to mammals but are absent from prokaryotes, unicellular yeasts, and plants (Benoist et al. 2006; Pöggeler and Kück 2004). The mammalian striatin family comprises the proteins striatin, zinedin and SG2NA, which are mainly expressed in neurons of the central nervous system. Within neurons, they display a typical polarized somato-dendritic localization, are absent from axons, and are highly concentrated in dendritic spines (Benoist et al. 2008; Castets et al. 1996; Gaillard et al. 2006; Kachidian et al. 1998).

Orthologues of the mammalian striatin proteins have been characterized in the goldfish Carassius auratus, the fruitfly 
Drosophila melanogaster, and in filamentous ascomycetes. They share a modular protein structure with their mammalian counterparts and have crucial functions in development (Chen et al. 2002; Ma et al. 2009; Pöggeler and Kück 2004; Shim et al. 2006; Simonin et al. 2010; Wang et al. 2010). The fungal orthologues PRO11 of $S$. macrospora, hyphal anastomosis 3 (HAM3) mutant of $N$. crassa, FSR1 from the plant pathogens Fusarium verticillioides and Fusarium graminearum as well as the Aspergillus nidulans StrA are involved in hyphal fusion, fruiting body development, and pathogenicity (Pöggeler and Kück 2004; Shim et al. 2006; Simonin et al. 2010; Wang et al. 2010). Functional conservation between fungal and animal striatins was demonstrated by the complementation of $S$. macrospora defects by mouse striatin (Pöggeler and Kück 2004).

Using a two-hybrid screen, Baillat et al. (2001) identified phocein/Mob3, a member of the monopolar spindleone-binder (Mob) family of proteins, as an interaction partner of the three rat striatin proteins (Baillat et al. 2001). Moreno et al. (2001) identified Mob3/phocein as a component of striatin/SG2NA-protein and phosphatase 2A (PP2A) complexes, using a proteomics approach. Recently, Goudreault et al. (2009) performed an iterative affinity purification/mass spectrometry approach to generate a high-density interaction map surrounding the mammalian PP2A catalytic subunit (PP2Ac), which identified Mob3 and striatin as part of a large multiprotein assembly referred to as striatin-interacting phosphatase and kinase (STRIPAK) complex. In addition to PP2Ac, striatin and Mob3, the STRIPAK complex contains the PP2A scaffolding subunit (PP2A A), the cerebral cavernous malformation 3 (CCM3) protein, several members of the germinal center kinase III family of Ste20 kinases, and the two novel proteins striatin-interacting protein (STRIP)1 and STRIP2 (Goudreault et al. 2009).

Mob proteins are conserved from yeasts to human. They share a characteristic core sequence, the mob domain (Baillat et al. 2001; Luca and Winey 1998; Ponchon et al. 2004). A phocein/Mob3 orthologue is absent in yeasts, but filamentous ascomycetes, D. melanogaster, and mammals encode a protein of the phocein/Mob3 subfamily (Chow et al. 2010; Maerz et al. 2009; Trammell et al. 2008).

In addition to its association with striatin, phocein/Mob3 also interacts with nucleoside-diphosphate kinase (NDPK), the clathrin associated protein Eps15, and dynamin, and therefore is thought to be involved in endocytosis and vesicular trafficking (Baillat et al. 2002). However, beyond the characterization of interactions and the localization in mammals, little is known about the function and interaction partners of phocein in other eukaryotes. In D. melanogaster, the phocein homologue DMob4 is involved in spindle focusing, synapse formation, axonal transport and microtubule organization (Schulte et al. 2010; Trammell et al.
2008). Moreover, the $N$. crassa phocein homologue MOB3 was recently shown to play a role in vegetative cell fusion and sexual development that is unrelated to nuclear Dbf2prelated (NDR) kinase signaling (Maerz et al. 2009). Many hyphal fusion mutants in $N$. crassa are also impaired in fruiting body development (Al Dabbous et al. 2010; Read et al. 2010; Simonin et al. 2010).

In this study, we focused on the isolation and functional characterization of the $S$. macrospora phocein homologue Smmob3. We demonstrate that SmMOB3 is essential for hyphal fusion and fruiting body development.

\section{Materials and methods}

Strains, media, and culture conditions

Cloning and propagation of recombinant plasmids was done in Escherichia coli strain SURE (Stratagene, LJ, USA) under standard culture conditions (Sambrook et al. 2001). For the homologous recombination experiments, Saccharomyces cerevisiae strain PJ69-4A was used as host strain and was cultivated as described by James et al. (1996). All strains used in this work are summarized in Table 1. S. macrospora strains were cultivated on corn meal medium (BMM) or fructification medium (SWG) (Elleuche and Pöggeler 2008; Esser 1982). For RNA extraction $S$. macrospora was grown for 3, 4, 5, 6 and 7 days in liquid BMM medium at $27^{\circ} \mathrm{C}$ in floating cultures to induce sexual reproduction conditions and in Erlenmeyer flasks with $100 \mathrm{ml}$ of liquid BMM medium shaken at $130 \mathrm{rpm}$ to induce vegetative development as described before (Nowrousian and Cebula 2005). RNA was then isolated from the sexually and vegetative induced cultures at the indicated time points. Determination of growth velocity and mycelial dry weight analysis were done as described elsewhere (Nolting and Pöggeler 2006a; Nowrousian and Cebula 2005). All experimental results are mean values of at least two independent measurements with three different samples each. Growth analysis of $S$. macrospora strains under stress inducing conditions was attained by cultivation for 7-10 days on solid SWG medium supplemented with $0.1 \mathrm{M} \mathrm{NaCl}$ or $\mathrm{KCl}, 0.4 \mathrm{M}$ sorbitol, $0.01 \%$ $\mathrm{H}_{2} \mathrm{O}_{2}$ or $0.003 \%$ SDS. For crossing of strains in the fusion assay, $0.25 \mathrm{~cm}^{2}$ pieces of agar overgrown with $S$. macrospora strains were arranged directly opposite to each other on a Petri dish with solid SWG medium and cultivated for 7-10 days at $27^{\circ} \mathrm{C}$. To determine the number of recombinant perithecia, a $1 \mathrm{~cm}$ agar-stripe of the crossing front was cut out from the plates. The crossing front was defined as an area of $0.5 \mathrm{~cm}$ left and right on both sides of the fusion line of crossed strains. All perithecia were harvested from this agarstripe and dissected and opened under a Zeiss "Stemi 2000-C" stereo microscope. To analyze hyphal self-fusion 
Table 1 Fungal strains used in this study

\begin{tabular}{|c|c|c|}
\hline Strain & Characteristics & Source \\
\hline \multicolumn{3}{|l|}{ Sordaria macrospora strains } \\
\hline S17736 & wild type & Lab collection ${ }^{\mathrm{a}}$ \\
\hline S23442 & fus-1, spore color mutant & Lab collection \\
\hline S66001 & $\Delta \mathrm{ku} 70:: \mathrm{nat}^{\mathrm{R}}$ & (Pöggeler and Kück 2006) \\
\hline S24117 & pro11 mutant & (Pöggeler and Kück 2004) \\
\hline pro11:r2 & ssi from cross pro1 1 mutant $\times$ spore color mutant $\mathrm{r} 2$ & Lab collection $^{\mathrm{a}}$ \\
\hline M 8871 & pro1 mutant & (Masloff et al. 1999) \\
\hline$\Delta$ Smmob3 & $\Delta$ Smmob3::hyg ${ }^{\mathrm{R}}$, ssi & This study \\
\hline$\Delta$ Smmob3:fus-1 & $\Delta$ Smmob3:: hyg $^{\mathrm{R}} /$ fus-1, ssi & This study \\
\hline$\Delta$ Smmob3_MOB3FL ${ }^{\text {ect }}$ & ectopic copy of full-length $S m m o b 3$ in $\Delta$ Smmob3; hyg ${ }^{\mathrm{R}}$, nat ${ }^{\mathrm{R}}$ & This study \\
\hline$\Delta$ Smmob3_MOB3N ${ }^{\text {ect }}$ & ectopic copy of $5^{\prime}$ Smmob3 (aa 1-264) in $\Delta$ Smmob3; hyg ${ }^{\mathrm{R}}$, nat ${ }^{\mathrm{R}}$ & This study \\
\hline$\Delta$ Smmob3_MOB3C ${ }^{\text {ect }}$ & ectopic copy of $3^{\prime}$ Smmob3 (aa 324-663) in $\Delta$ Smmob3; hyg $^{\mathrm{R}}$, nat ${ }^{\mathrm{R}}$ & This study \\
\hline wt_trpC-PRO11si ${ }^{\text {ect }}$ & wt transformed with pPro11si, nat ${ }^{\mathrm{R}}$ & This study \\
\hline wt_trpC-MOB3si ${ }^{\text {ect }}$ & wt transformed with pMob3si, nat ${ }^{\mathrm{R}}$ & This study \\
\hline pro11_trpC-MOB3 $\mathrm{si}^{\mathrm{ect}}$ & pro11 mutant transformed with pMob3si, nat ${ }^{\mathrm{R}}$ & This study \\
\hline$\Delta$ Smmob3_trpC- PRO11 $\mathrm{si}^{\text {ect }}$ & $\Delta$ Smmob3 transformed with pPro11si, hyg ${ }^{\mathrm{R}}$, nat ${ }^{\mathrm{R}}$ & This study \\
\hline$\Delta$ Smmob3_gpd-MOB3 & ectopic copy of Smmob3 under control of A. nidulans gpd promoter, nat ${ }^{\mathrm{R}}$, ssi & This study \\
\hline
\end{tabular}

ect ectopic copy, trpC and gpd under control of Aspergillus nidulans trpC or gpd promoter, $F L$ full-length, $N \mathrm{~N}$-terminal part, $C \mathrm{C}$-terminal part, $n a t$ nourseothricin-cassette, $h p h$ hygromycin-cassette, ssi single spore isolate, $h y g^{R}$ hygromycin resistant, nat $^{R}$ nourseothricin resistant

${ }^{a}$ Department of General and Molecular Botany, Ruhr University of Bochum, Germany

events in the $S$. macrospora wt and $\Delta$ Smmob3 colonies, strains were cultivated on MMS minimal medium according to Rech et al. (2007) and Bloemendal et al. (2010) with the following modifications. MMS covered glass slides were layered with one sheet of cellophane (Biorad, Hercules, USA) and $S$. macrospora strains were inoculated atop. After $48 \mathrm{~h}$ of incubation, cellophane sheets with grown colonies were removed from the MMS and placed upside-down with A. dest on a glass slide for microscopic investigation.

\section{Transformation procedures}

For each transformation $100 \mathrm{ng}$ of plasmid DNA or PCR fragments were used. Transformation by electroporation was carried out using $0.2 \mathrm{~cm}$ cuvettes (ThermoFisher Scientific, Waltham, USA) in an Eppendorf Electroporator 2510 (Eppendorf, Hamburg, Germany) at $2.5 \mathrm{kV}$ for the transformation of E. coli (Song et al. 1993) and at $1.5 \mathrm{kV}$ for transformation of $S$. cerevisiae (Becker and Lundblad 2001). Transformation of $S$. macrospora was done as described before (Nowrousian et al. 1999; Pöggeler et al. 1997a). For generation of protoplasts $20 \mathrm{mg} / \mathrm{ml}$ Glucanex 200G (Schliessmann, Schwäbisch Hall, Germany) was used. Transformants were selected either on solid hygromycin B- $(110 \mathrm{U} / \mathrm{ml})$ and/or nourseothricin-dihydrogen sulfate-containing BMM medium $(50 \mu \mathrm{g} / \mathrm{ml}$; clonNat, Werner-BioAgents, Jena, Germany).
Preparation of nucleic acid and PCR

Plasmid DNA was purified from $S$. cerevisiae using the QIAprep Spin Miniprep Kit (Qiagen, Hilden, Germany) with the following modification. $250 \mu \mathrm{l}$ of buffer P1 were added to the harvested cells. To break the cell wall, glass beads were added to the cells and the suspension was mixed for $5 \mathrm{~min}$ on a vortex mixer. Isolation of $S$. macrospora genomic DNA was carried out as described previously (Pöggeler et al. 1997b). Total RNA isolation of $S$. macrospora strains and reverse transcription was carried out as described before (Elleuche and Pöggeler 2009). All restriction endonucleases and ligases were purchased from Fermentas (St-Leon Rot, Germany). For PCR experiments Phusion ${ }^{\circledR}$ Hot Start High-Fidelity DNA Polymerase from Finnzymes (Espoo, Finland) and MolTaq DNA polymerase (Molzym, Bremen, Germany) were used according to the manufacturer's manual. Oligonucleotides were obtained from Eurofins MWG Operon (Ebersberg, Germany) and are summarized in Table 2. Plasmids used in this study are listed in Table 3.

Sequence analysis

DNA sequencing was performed by Eurofins MWG Operon (Ebersberg, Germany) or by the sequencing service of the $\mathrm{G}_{2} \mathrm{~L}$ Genome Laboratory (Georg-August University 
Table 2 Oligonucleotides used in this study a Restriction sites used for plasmid construction are underlined and oligonucleotide overhangs for homologous recombination are given in italics

\begin{tabular}{|c|c|}
\hline Oligo & Specific sequence $\left(5^{\prime}-3^{\prime}\right)^{\mathrm{a}}$ \\
\hline pho1-5f & GTAACGCCAGGGTTTTCCCAGTCACGACG GGAATCGAGCGAACTTTACA \\
\hline pho1-5r & ССАААААТGCТССТTСААТАТСАGTTAАC CCCAACAATGAGGTTATTGC \\
\hline pho1-3f & GAGTAGATGCCGACCGGGAACCAGTTAAC AGCACAGCGAACACAAGAGG \\
\hline pho1-3r & GCGGATAACAATTTCACACAGGAAACAGC CTAGTCCACCTTTGGGGCCT \\
\hline hph-f & GTTAACTGATATTGAAGGAGCATTTTTGG \\
\hline hph-r & GTTAACTGGTTCCCGGTCGGCATCTACTC \\
\hline pho1-14f & CCCCGACATATCGAATCCAGC \\
\hline pho1-2r & CCCCTAATGATGCCTCTACGC \\
\hline $\operatorname{trpC} 1$ & GATCCGCCTGGACGACTAAACC \\
\hline hph3 & ACTCGTCCGAGGGCAAAGGAATAG \\
\hline pho1-15f & AGGACCAACACGAGGCGGCAT \\
\hline Smpho1-14 & GGCAGTGCCCTGACTACTGTT \\
\hline GAL4-T7 & AATACGACTCACTATAGGGCTCTA \\
\hline Smpho1_Orf-r & GGAGAGCTTAGAGGAAGCGACAT \\
\hline NCU11371_r & GAGCATCGTCGTCGTAGTCCAT \\
\hline Smpho1-13 & GTCGACAACAGTAGTCAGGGGACTGCC \\
\hline pho1frodo-f & CTTCTGGGTCTGCCAATGAT \\
\hline pho1frodo-r & CTCTTGGGCGGTGTTTGTAT \\
\hline pro11frodo-f & GTTCTGGTCCCTCGAAACAA \\
\hline pro11frodo-r & ACCTCGCATACACCTTGACC \\
\hline SSU-f & ATCCAAGGAAGGCAGCAGGC \\
\hline SSU-r & TGGAGCTGGAATTACCGCG \\
\hline pho5f_2 & GTAACGCCAGGGTTTTCCCAGTCACGACG GTCGTGGATCACACAAACGT \\
\hline pho5r_2 & GATGGTTCTTCGCTCTCTGAGC \\
\hline phodom2_r & ССАAАAATGCTCCTTCAATATCAGTTAACAGGAAGCTGGAAGTTCTCGT \\
\hline phodom3_f & GCATCGCGCTCAGAGAGCGAAGAACCATC ATGAGGACCAACACGAGGCG \\
\hline phoORF-f & ATGTCGCTTCCTCTAAGCTCTC \\
\hline phocDNA-2r & AGGAAGCTGGAAGTTCTCGT \\
\hline phocDNA-3f & ATGAGGACCAACACGAGGCG \\
\hline phoORF-r & GTCCACCTTTGGGGCCTGCT \\
\hline pho-sense-f & CTCGAGAGGACCAACACGAGGC \\
\hline pho-sense-r & AAGCTTGTTGCCTGGCTGTATTAC \\
\hline pho-antisense-f & GGGCCCAGGACCAACACGAGGC \\
\hline pho-antisense-r & AGATCTGTTGCCTGGCTGTATTAC \\
\hline 11-sense-f2 & $\underline{\text { CTCGAGGGAGCCCCTAACGAAGCT }}$ \\
\hline 11-sense-r & $\underline{\text { AAGCTTCCAGTCGGGGGTTTCA }}$ \\
\hline 11-antisense-f2 & $\underline{\text { GGGCCCGGAGCCCCTAACGAAGCT }}$ \\
\hline 11-antisense-r & AGATCTCCAGTCGGGGGTTTCA \\
\hline pRSGPDf2 & GTAACGCCAGGGTTTTCCCAGTCACGACG GTACAGTGACCGGTGACTCT \\
\hline phorevGPD & AGCCGAGGAGAGCTTAGAGGAAGCGACATTAGCTGTTAGTCAAGCTGCG \\
\hline phofGFP & CTGTCGCTGAGCAGGCCCCAAAGGTGGACATGGTGAGCAAGGGCGAGGA \\
\hline pRSGFPrev & GCGGATAACAATTTCACACAGGAAACAGCTCGAGTGGAGATGTGGAGTG \\
\hline
\end{tabular}

of Göttingen, Göttingen, Germany). Protein sequence alignments were conducted using the ClustalX program (Thompson et al. 1997). Protein and nucleotide sequence data of MOB3 proteins from other organisms were obtained from the public databases at NCBI (http://www. ncbi.nlm.nih.gov/entrez/) or by BLAST searches (Altschul et al. 1997) of sequenced fungal genomes at the Broad Institute (http://www.broad.mit.edu/annotation/fungi/fgi/). The degree of identity between two sequences was designated at the LALIGN Server (http://www.ch.embnet. org) (Huang and Miller 1991). Promoter elements were predicted by using the Promoter Predictor 
Table 3 Plasmids used in this study

\begin{tabular}{|c|c|c|}
\hline Plasmid & Insert & Reference \\
\hline pRS246 & $U R A 2$ & Christianson et al. (1992) \\
\hline pRSnat & URA2, nat-cassette & Klix et al. (2010) \\
\hline pS-NAT1 & $\begin{array}{l}\operatorname{trpC} \text { promoter and terminator of } A \text {. nidulans, cutinase intron } 2 \\
\text { of } M . \text { oryzae, gpd promoter of A. nidulans and nat } 1 \text { gene }\end{array}$ & Janus et al. (2007) \\
\hline pMob3FL & Full-length SmMob3 in pRSnat & This study \\
\hline pMob3N & $5^{\prime}$ region (aa 1-264) of $S m M o b 3$ in pRSnat & This study \\
\hline pMob3C & $3^{\prime}$ region (aa 324-663) of $S m M o b 3$ in pRSnat & This study \\
\hline pMob3ko & $\begin{array}{l}700 \text { bp } 5^{\prime} \text { and } 959 \text { bp } 3^{\prime} \text { region of } S m M o b 3 \text { and flanking regions } \\
\text { separated by the } h p h \text {-cassette }\end{array}$ & This study \\
\hline pMob3oex & SmMob3 regulated by $g p d$ promoter and $\operatorname{trp} C$ terminator of $A$. nidulans & This study \\
\hline pPro11si & 471 bp part of proll in pS-NAT1 & This study \\
\hline pMob3si & 500 bp part of $S m M o b 31$ in pS-NAT1 & This study \\
\hline
\end{tabular}

Sm S. macrospora

(http://www.fruitfly.org/seq_tools/promoter.html) (Reese 2001). The molecular weight, isoelectric point, and phosphorylation sites of the SmMOB3 protein were calculated with programs from the ExPASy Proteomics Server (ProtParam, and NetPhos at http://www.expasy.org) (Blom et al. 1999; Gasteiger et al. 2005).

Cloning of the Smmob3 gene

A high throughput PCR screening of an indexed S. macrospora cosmid library (Pöggeler et al. 1997a) and a PCR screening of a $S$. macrospora cDNA library (Nolting and Pöggeler 2006b) with primers Smpho1-14 and GAL4-T7 led to the cloning of the complete Smmob3 ORF (2,078 bp) and including $212 \mathrm{bp}$ of the downstream region. A 716-bp upstream region of the Smmob3 ORF was amplified from $S$. macrospora genomic DNA by using primer NCU11371_r, which was designed according to the conserved sequence of $N$. crassa ORF NCU11371 and S. macrospora specific primer Smpho1_Orf-r. The nucleotide sequence of the $S$. macrospora Smmob3 gene has been denoted in the EMBL database under accession number FN995002.

\section{Quantitative real-time PCR}

Quantitative real-time PCR using a Mastercycler ${ }^{\circledR}$ ep realplex (Eppendorf, Hamburg, Germany) was carried out as described before (Elleuche and Pöggeler 2009). Realtime experiments were conducted at least two times in triplicates with independent biological samples. Primer pair pholfrodo-f/pho1frodo-r was used to amplify a 233-bp part of the Smmob3 gene. Primer combination pro11frodo-f/ pro11frodo-r resulted in the amplification of a 152-bp part of the proll gene. Amplification of a part of the small-subunit rRNA with primers SSU-f and SSU-r was used as a reference for normalization of $\mathrm{Ct}$ values.

Construction of a Smmob3 disruption strain

A Smmob3 disruption strain was generated by using a deletion construct based on homologous recombination in yeast (Colot et al. 2006). A 700-bp 5'- and a 959-bp 3'fragment of Smmob3 was amplified from genomic DNA of the $S$. macrospora wt with primer pair pho1-5f/pho1-5r and pho1-3f/pho1-3r, respectively. PCR reactions created specific 29 bp overhangs to the $5^{\prime}$ - and $3^{\prime}$-Smmob3 fragments, homologous to the yeast plasmid pRS426 (Christianson et al. 1992) and the hygromycin-resistance cassette (hph), respectively. The $h p h$ cassette was amplified from plasmid pCB1003 (Carroll et al. 1994) using primers hph-f and hphr. For homologous recombination all three PCR fragments were co-transformed with EcoRI/XhoI linearized plasmid pRS426 into yeast strain PJ69-4A. The resulting plasmid pMob3ko was isolated from yeast and used as a template to amplifiy the Smmob3-disruption cassette with primers pho1-5f/pho1-3r. The obtained linear 3015-bp PCR fragment was transformed into a $S$. macrospora $\Delta \mathrm{ku} 70$ strain to facilitate homologous recombination. In the $S$. macrospora $\Delta \mathrm{ku} 70$ strain the $k u 70$ gene was exchanged by a nourseothricin resistance cassette (Pöggeler and Kück 2006). Heterokaryotic primary transformants were screened for homologous recombination by PCR using primer combination pho1-14f/pho1-2r. Afterwards, single spore isolates of the primary transformants were screened for homokaryotic $\Delta$ Smmob3::hyg/ $\Delta \mathrm{ku} 70:$ :nat genotype on hygromycin $\mathrm{B}$ and nourseothricin containing BMM medium. Candidate primary transformants were subsequently crossed with spore color mutant fus- 1 and ascospores were isolated from 
hybrid perithecia. Finally, the desired hygromycin resistant, nourseothricin sensitive $\Delta \mathrm{Smmob} 3$ strain was verified by PCR and Southern blot. Southern blotting and hybridization were performed according to standard techniques (Sambrook et al. 2001) A 959-bp Smmob3 3'-fragment amplified from genomic $S$. macrospora wt DNA with primer pair pho1-3f/pho1-3r was labeled with ${ }^{32} \mathrm{P}$ and used as DNA probe. Transcriptional expression of $5^{\prime}$ - and $3^{\prime}-$ Smmob3 parts in wt and $\Delta$ Smmob3 was tested by qualitative RT-PCR analysis using RNA from both strains as template. $5^{\prime}$-fragments were amplified with primer pair phoORF-f/phocDNA-2r and $3^{\prime}$-fragments were amplified with primer pair phocDNA-3f/phoORF-r.

\section{Complementation analysis in S. macrospora}

To verify the functionality of the Smmob3 gene and to determine functional domains of SmMOB3, vectors pMob3FL, pMob3N pMob3C and pMob3oex were generated using the yeast-based homologous recombination system (Colot et al. 2006). Full-length Smmob3 and truncated versions of the gene, respectively, were amplified together with the upstream region of the Smmob3 gene, containing the putative Smmob3 promoter region and were cotransformed with XhoI-linearized vector pRSnat, into yeast strain PJ69-4A. Vector pRSnat is a derivative of plasmid pRS426. It contains the natl gene, which mediates nourseothricin-resistance, under control of the $\operatorname{trpC}$ promoter of A. nidulans (Klix et al. 2010). The Smmob3 gene fragments containing the putative Smmob3 promoter region in plasmids pMob3FL (full-length SmMOB3 aa 1-663) and pMob3N (aa 1-264) were generated in a PCR with primer pairs pho5f_2/pho1-3r and pho5f_2/phodom2_r, respectively, which contain 29 bp overhangs specific to pRSnat using $S$. macrospora wt genomic DNA as template. To generate plasmid pMob3C, the putative promoter region and C-terminal coding region (aa 324-663) of Smmob3 were amplified individually with primer pairs pho5f_2/pho5r_2 and phodom3_f/ pho1-3r. Overexpression-vector pMob3oex plasmid carries Smmob3 under control of the A. nidulans gpd and the $\operatorname{trpC}$ terminator. The gpd and $\operatorname{trpC}$ fragments were amplified with primer pairs pRSGPDf2/phorevGPD and phofGFP/pRSGFPrev using plasmid p1783-1 (Pöggeler et al. 2003) as template. Full-length Smmob3 was obtained by PCR with primer phoORF-f/phoORF-r using wt genomic DNA as a template. The three fragments were subsequently transformed together with XhoI linearized pRSnat (Klix et al. 2010) into yeast strain PJ69-4A. All plasmids were transformed into $S$. macrospora $\Delta$ Smmob3 strain and were selected on nourseothricin-containing BMM medium.
Smmob3- and pro11-RNAi vector construction

For the construction of RNAi silencing vectors pMob3si and pPro11si two 500-bp fragments of the Smmob3 and proll coding region, respectively, were amplified with primer pairs pho-sense-f/pho-sense-r, pho-antisense-f/pho-antisense-r and 11-sense-f2/11-sense-r, 11-antisense-f2/11-antisense-r using wt genomic DNA as template. The obtained fragments were subcloned and sequenced, and after excision with XhoI/ HindIII and ApaI/BglII, respectively, inserted in sense and antisense orientation in vector pS-NAT1 (Janus et al. 2007). Vector pMob3si and pPro11si were transformed into $S$. macrospora wt. Transformants were selected on BMM medium containing nourseothricin. In addition, pPro11si was transformed into $\Delta$ Smmob3 strain and pMob3si was transformed into the pro11 mutant. Again transformants were selected on nourseothricin containing medium. The expression levels of Smmob3 and proll in the RNAi transformants were determined by quantitative real-time PCR.

\section{FM4-64 dye loading}

Analysis of endocytosis was performed according to Fischer-Parton et al. (2000) with following modification. $20 \mu \mathrm{l}$ of a $1 \mu \mathrm{M}$ FM4-64 solution (Invitrogen, San Diego, USA) was applied directly on wt and $\Delta$ Smmob3 hyphae grown on SWG covered glass slides.

\section{Microscopic investigations}

For light microscopic analysis of $S$. macrospora, strains were cultivated at $27^{\circ} \mathrm{C}$ for $3-7$ days on glass slides coated with a thin layer of solid SWG medium or for 7-10 days on Petri dishes with solid BMM medium. To visualize the ascogonia and protoperithecia the AxioImager M1 microscope (Zeiss, Jena, Germany) was used. Images were captured with a Photometrics CoolSNAP ${ }_{\mathrm{HQ}}^{2}$ camera (Roper Scientific, Photometrics, Tucson, Arizona). Detection of FM4-64 dye was carried out using chroma filter set 49005 (excitation/emission filter ET545/30/ET620/60, beam splitter T570lp) and an X-cite 120 PC lamp (EXFO, ON, Canada). Recorded images were edited with MetaMorph (VisitronSystems, Puchheim, Germany) and Adobe Photoshop CS2. The Digital Microscope VHX-500F with objective lens VH-Z20R RZx20-x150 (Keyence, Osaka, Japan) was used to take pictures of perithecia and ascus rosettes. To determine the density of protoperithecia per $1 \mathrm{~cm}^{2}$, SWG covered glass slides were inoculated with the wt, pro11 or $\Delta$ Smmob3. After 7 days of growth at $27^{\circ} \mathrm{C}$ all protoperithecia produced on an area of $1 \mathrm{~cm}^{2}$ were counted under the microscope. The experiment was carried out twice with two biologically independent samples. 


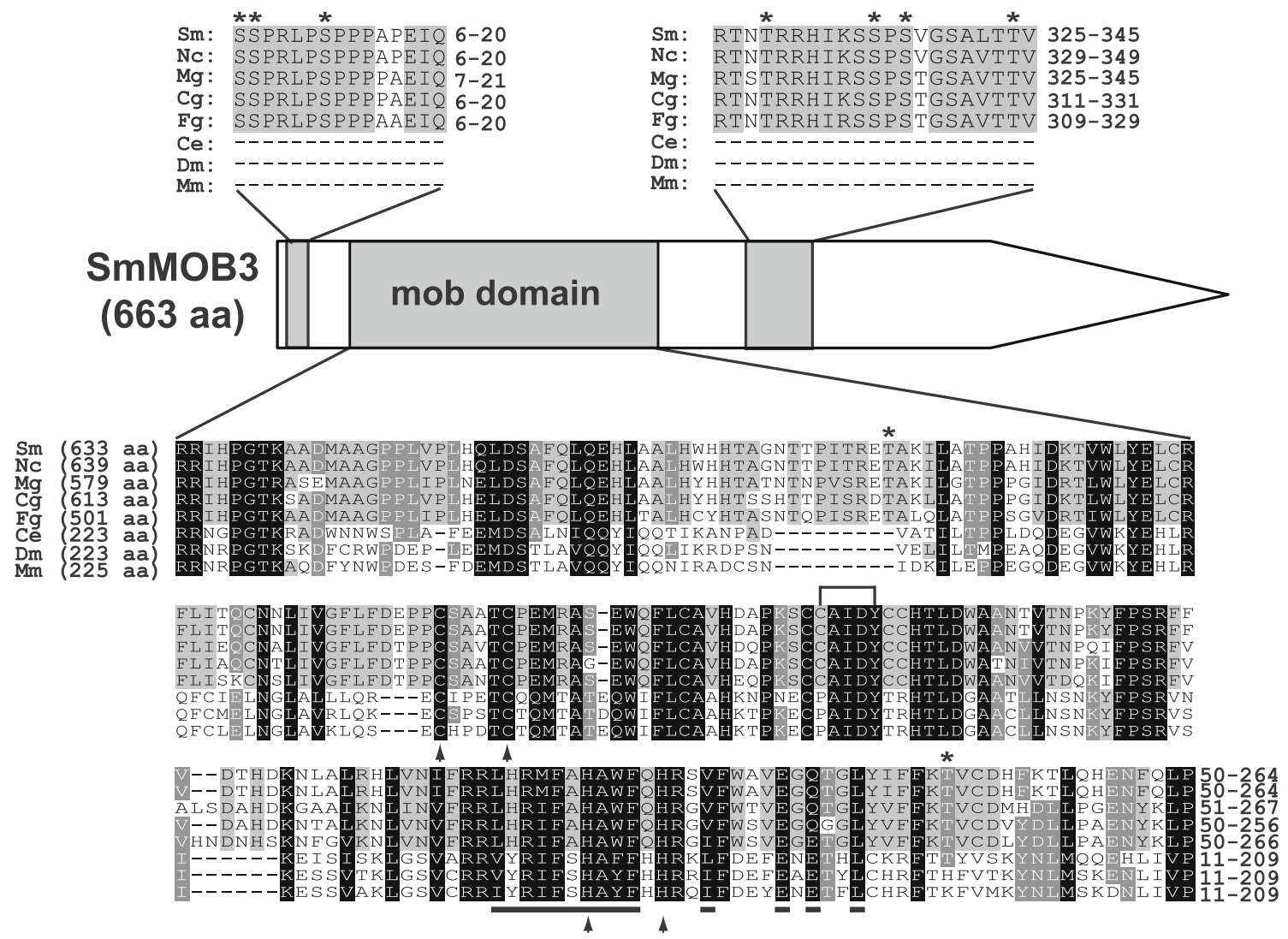

Fig. 1 Multiple sequence alignment of MOB3 proteins in filamentous ascomycetes and vertebrates. The white arrow represents the $S$. macrospora SmMOB3 protein with the mob domain, and two fungal specific, conserved N- and C-terminal domains (grey boxes). Sequences of fungal and animal origin were aligned with ClustalX. Sm, Sordaria macrospora (accession number FN995002); Nc, Neurospora crassa (XP_328380.1); Mg, Magnaporthe grisea (MG07095.4); Cg, Chaetomium globosum (XP_001223910.1); Fg, Fusarium graminearum (FGSG_05101.2); Ce, Caenorhabditis elegans (NP_498798.2); Dm, Drosophila melanogaster (NP_610229.1); Mm, Mus musculus (NP_079559.2). Amino acid residues conserved

\section{Results}

S. macrospora Smmob3 encodes a phocein homologue

We isolated the phocein homologue Smmob3 from $S$. macrospora. Recently, N. crassa NCU07674 was shown to encode a phocein/Mob3 homologue involved in vegetative cell fusion, fruiting body development, and ascosporogenesis (Maerz et al. 2009). The N. crassa and S. macrospora genomes share a high degree of synteny and nucleotide identity, with an average of $89.5 \%$ identity within exons (Nowrousian et al. 2004). Therefore, Smmob3 was amplified with $N$. crassa-derived primers from an indexed $S$. macrospora cosmid library and a cDNA library (Nolting and Pöggeler 2006b; Pöggeler et al. 1997a). The Smmob3 open reading frame (ORF) consists of $2078 \mathrm{bp}$, in all sequences are shaded in black, residues conserved in at least seven sequences are shaded in dark grey and residues conserved in at least five sequences are shaded in light grey. Dashes represent aa that do not exist in the indicated protein sequence. The aa regions used for the alignment are given on the right. Stars above the alignment denote predicted serine and threonine phosphorylation sites. A putative SH3binding motif is marked by a bracket and a sequence region with homology to the clathrin adaptor complexes small chain signature of the $\sigma$ subunits (I, L, V, M) (I, L, V, M) YRxxxxLYF is marked by black bold lines. The conserved putative Cys2-His2 Zn binding sites are marked by black arrows

encoding a protein of 663 amino acids (aa) with a predicted molecular mass of $72 \mathrm{kDa}$ and an isoelectric point of 4.6. Comparison of the genomic and cDNA sequences of Smmob3 revealed one intron of 86 bp at position 216/217 of the ORF (data not shown). The Promotor Prediction program (Reese 2001) predicted a transcriptional start site 336 nucleotides upstream of the putative ATG start codon of the Smmob3 gene. The flanking sequences of this putative start display a high level of similarity to translation initiation sites of other $S$. macrospora genes (Pöggeler 1997). Database searches revealed MOB3 proteins in the genomes of closely related fungi such as Chaetomium globosum and in more distantly related filamentous ascomycetes, e.g. Magnaporthe grisea and F. graminearum, and in animals (Fig. 1). However, no Mob3 proteins were found in the genomes of hemiascomycetous yeasts. 
Interestingly, $\mathrm{N}$ - and $\mathrm{C}$-terminal extensions in the filamentous ascomycetes MOB3 proteins result in proteins that are about three times longer than Mob3 proteins of animals (Fig. 1). Two highly conserved regions specific to filamentous ascomycetes were identified in the $\mathrm{N}$ - and $\mathrm{C}$-termini, respectively (Fig. 1). The highest degree of aa identity was identified within the conserved mob domain of 180-200 aa length.

Aside from these domains and the mob domain, similarity among fungal MOB3 proteins was limited in the N(46-96\%) and C-terminal extensions (19-65\%). Mob3 proteins may act in protein complexes with serine/threonine protein phosphatases and kinases (Goudreault et al. 2009), so putative phosphorylation sites of SmMOB3 were predicted using the Netphos program (Blom et al. 1999). We identified 36 out of 52 serines, and 21 out of 57 threonines in SmMOB3 that were predicted to be phosphorylated, most located within the ascomycete-specific $\mathrm{N}$ - and C-terminal regions (data not shown). When compared to the putative serine and threonine phosphorylation sites of NcMOB3 and MgMOB3, seven serine and five threonine residues were conserved among all three fungi, mostly in the conserved regions (Fig. 1). Similar to mammalian phocein, a domain homologous to a clathrin adaptor complexes small chain signature of the $\sigma$ subunits, and a sequence similar to a SH3-binding domain of the type PxxDY were identified in SmMOB3 and other fungal MOB3 homologues (Baillat et al. 2001). Moreover, a putative Cys2-His2 $\mathrm{Zn}$ binding site that is conserved in proteins of the Mob family is also present in SmMOB3 (Stavridi et al. 2003; Vitulo et al. 2007).

\section{Smmob3 and pro11 expression is increased}

during sexual development

To determine when Smmob3 and proll are expressed in $S$. macrospora, quantitative real-time PCR experiments were performed. Under our experimental conditions, sexual development starts 3 days after inoculation with ascogonia formation, followed by the development of pre-fruiting bodies (protoperithecia) at days 4-5, and ending after 7 days, with the discharge of mature ascospores from the fruiting bodies (perithecia). Transcript levels of Smmob3 and proll in the wildtype (wt) under vegetative growth conditions were compared to the expression under sexual growth conditions after 3, 4, 5, 6 and 7 days of development, respectively. Our data revealed a significant and similar upregulation of Smmob3 and proll transcripts at days 3, 4, 5 and 6 (Fig. 2). Expression of both genes was upregulated at all stages of sexual development, with the highest mRNA abundance in late phase (day 6) of sexual development. In addition proll is strongly abundant at day 3 of development.

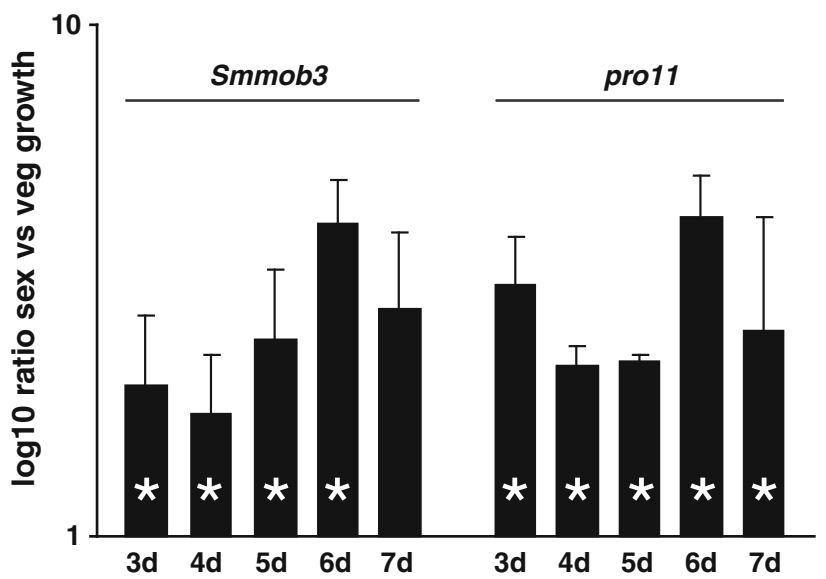

Fig. 2 Expression analysis of the Smmob3 and proll gene by quantitative real-time PCR. Expression of Smmob3 and proll was compared in sexually (sex) and vegetative (veg) grown wt at the indicated days of sexual development (3-7 days). Values shown represent mean expression ratios of at least two independent biological samples, each done in triplicates. Standard deviations as indicated. Asterisks indicate significance calculated according to REST (Pfaffl et al. 2002)

Disruption of Smmob3 leads to an impaired vegetative growth and sterility

In $N$. crassa, MOB3 is required for vegetative cell-cell fusion, and during sexual development (Maerz et al. 2009). To elucidate the function of Smmob3 in the homothallic $S$. macrospora, Smmob3 was disrupted with a hygromycinresistance cassette as described in the "Materials and methods". Homologous integration of the deletion construct into the Smmob3 gene locus led to the replacement of a 654-bp fragment of Smmob3 encoding more than half of the conserved mob domain and the entire, fungal-specific C-terminus, with the hygromycin-resistance cassette (Fig. S1). After transformation, four heterokaryotic hygromycinand nourseothricin-resistant primary transformants con-

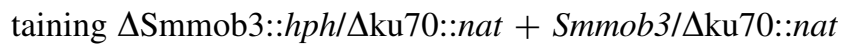
nuclei were isolated, and homologous integration was confirmed by PCR (data not shown). To obtain a homokaryotic $\Delta$ Smmob3::hph strain in a wt background, a primary transformant was subjected to conventional genetic analysis. Genetic analysis of 15 ordered tetrads from $\Delta$ Smmob3 $\times$ fus- 1 crosses showed that the sterile phenotype of $\Delta$ Smmob3 segregated in a 4:4 Mendelian manner, and that sterility was linked to $h p h$ resistance, indicating that disruption of the Smmob3 gene was responsible for the sterile phenotype.

The $\Delta$ Smmob3 strain was confirmed by PCR and Southern blot (Fig. S1), and was phenotypically analyzed. To verify that no transcript of the partial Smmob3 ORF is produced by the mutant strain, we performed a qualitative 
A

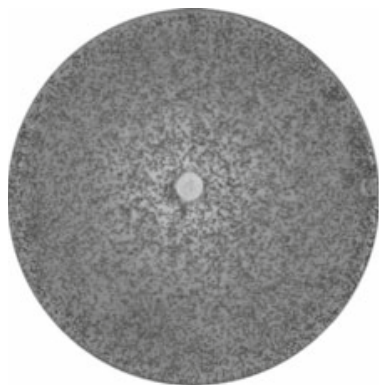

wt

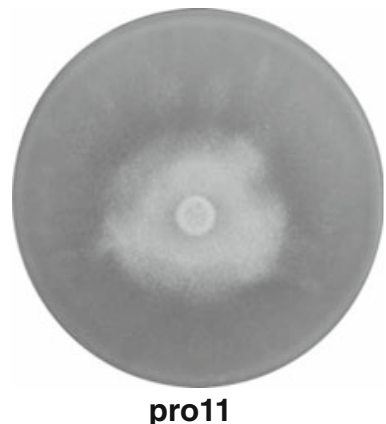

pro11

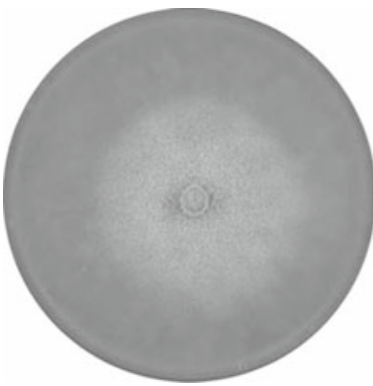

$\Delta$ Smmob3

B ascogonium protoperithecium pig. protoperithecium

perithecia
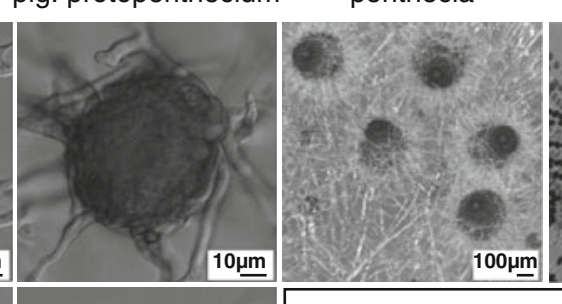

ascospores
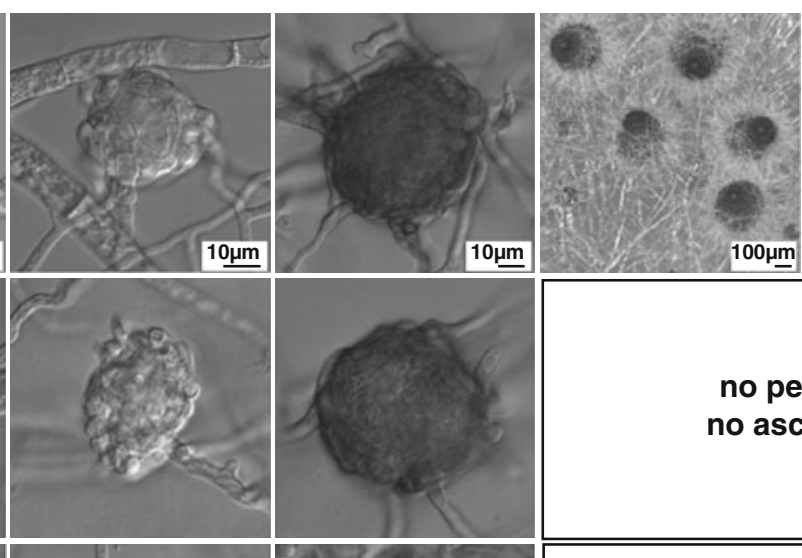

no perithecia

no ascospores

\section{$\Delta$ Smmob3}
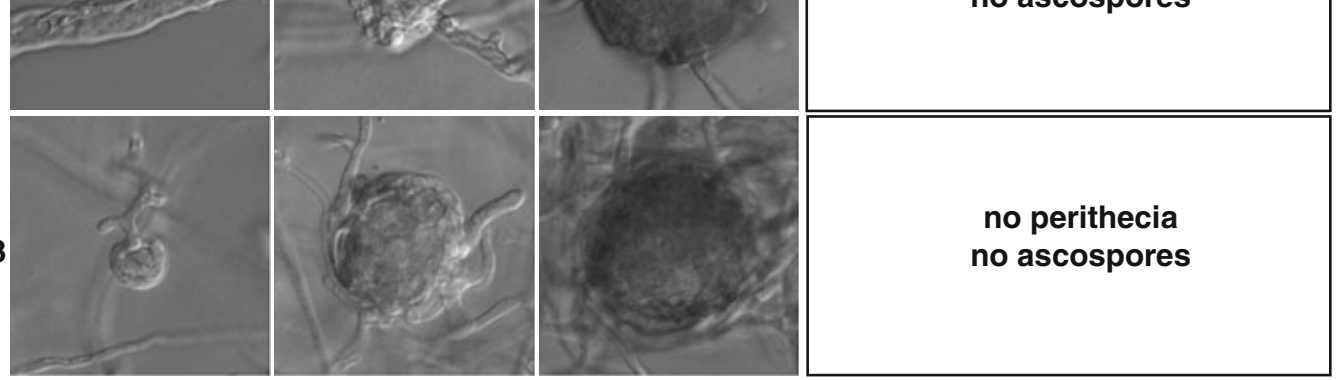

C

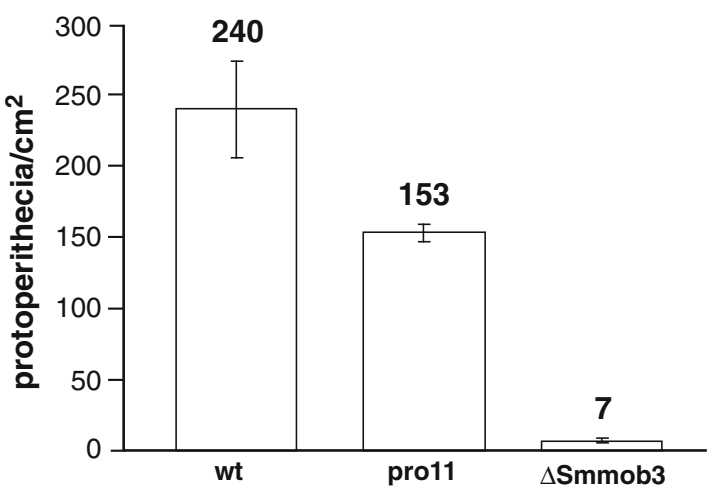

Fig. 3 Macroscopic and microscopic analysis of fruiting body and ascospore development of $S$. macrospora wt, pro11 and $\Delta$ Smmob3 strains. a Phenotypes of wt, mutant pro11, and $\Delta$ Smmob3 after 10 days of growth on solid SWG at $27^{\circ} \mathrm{C}$. b Microscopic investigation of sexual structures of wt, pro 11 , and $\Delta$ Smmob3. Abbreviation:

RT-PCR. As shown in Figure S1 no transcript of the ORF could be detected.

Compared to the wt, $\Delta$ Smmob3 showed reduced vegetative growth after incubation for 7 days on fructification pig.-pigmented. c Protoperithecia ranging in size of 40-200 $\mu \mathrm{m}$ of wt, pro1 1 and $\Delta$ Smmob3 strain were counted per square centimeter after 7 days of growth on SWG coated glass slides under the microscope. Error bars as indicated

medium (SWG), and complete lack of fruiting body formation (Fig. 3a). Furthermore, the density of aerial hyphae was strongly increased in the $\Delta$ Smmob3 mutant, giving the mycelium a cotton-like appearance, as described 
previously for the pro11 mutant. The pro11 mutant allele differs from the wild-type proll gene by a single point mutation within the coding region, resulting in an in-frame stop codon (TGG Trp to TGA stop) at amino acid position 546 of PRO11 (Pöggeler and Kück 2004). Vegetative mycelial extension was analyzed by determination of growth rate in race tubes and by dry weight measurement. On SWG medium, the daily mycelial extension of $\Delta$ Smmob3 was strongly reduced $(8 \pm 3 \mathrm{~mm} /$ day $)$ compared to the wt $(23 \pm 4 \mathrm{~mm} /$ day $)$ and the pro11 mutant (18 $\pm 2 \mathrm{~mm} /$ day). In addition, the biomass of $\Delta$ Smmob3 was reduced to $1 \pm 0.4 \mathrm{mg} / \mathrm{ml}$ mycelium compared to $6 \pm 0.5 \mathrm{mg} / \mathrm{ml}$ for the wt control after 7 days of growth in liquid SWG medium. A microscopic analysis revealed a wt-like septation and polarized growth. The mammalian phocein has been linked to endocytosis (Baillat et al. 2002), therefore we tested endocytosis in the $\Delta$ Smmob3 mutant by a FM4-64 uptake assay. However, we observed no differences between the wt and the mutant strain (Fig. S2).

To analyze the effects of Smmob3 disruption on multicellular development, the formation of sexual reproductive structures was examined. Similar to the wt and the pro11 mutant, $\Delta$ Smmob3 generated ascogonia and protoperithecia. However, as shown in Fig. 3b, fertile fruiting bodies and ascospores were not observed, even after prolonged incubation. Thus, similar to pro11, $\Delta$ Smmob3 was sterile. To compare the ability to develop sexual structures, we investigated the number of protoperithecia produced per square centimetre by wt, mutant pro11, and $\Delta$ Smmob3 (Fig. 3c). As described previously, the pro11 mutant exhibited a decreased number of protoperithecia compared to the wt $\left(240 \pm 34\right.$ protoperithecia/ $\left.\mathrm{cm}^{2}\right)$ (Pöggeler and Kück 2004). Interestingly, this effect was much more pronounced in $\Delta \mathrm{Smmob} 3\left(7 \pm 1\right.$ protoperithecia $\left./ \mathrm{cm}^{2}\right)$ than in pro11 $\left(153 \pm 6\right.$ protoperithecia $\left./ \mathrm{cm}^{2}\right)$.

To test the influence of stress-inducing agents on growth of $\Delta \mathrm{Smmob3}$, wt and $\Delta \mathrm{Smmob3}$ were cultivated on SWG supplemented with different concentrations of $\mathrm{H}_{2} \mathrm{O}_{2}$, SDS, $\mathrm{NaCl}, \mathrm{KCl}$ or sorbitol. However, no differences between wt and $\Delta$ Smmob3 were found (data not shown).

The N-terminal domain of SmMOB3 is essential for protein function

To characterize the functional domains of SmMOB3, plasmids pMob3FL, pMob3N and pMob3C (described in "Materials and methods") encoding the full-length Smmob3 or fragments coding for the N-terminal or C-terminal domains, were transformed into the $\Delta$ Smmob3 mutant strain (Fig. 4a). The resulting transformants $\Delta$ Smmob3_MOB3FL ${ }^{\text {ect }}, \quad \Delta$ Smmob3_MOB3N ${ }^{\text {ect }}$ and $\Delta$ Smmob3_MOB3C ${ }^{\text {ect }}$ were phenotypically analyzed (Fig. 4b). As shown in Fig. 4b, ectopically integrated full-
A

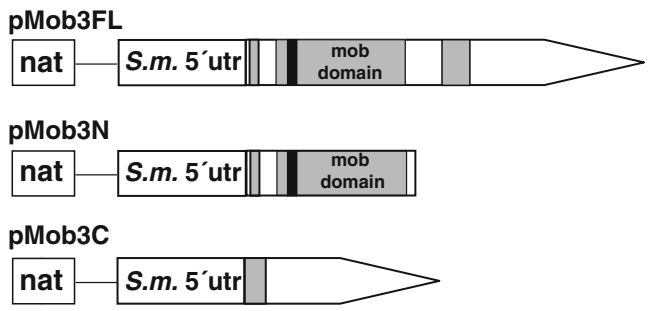

B

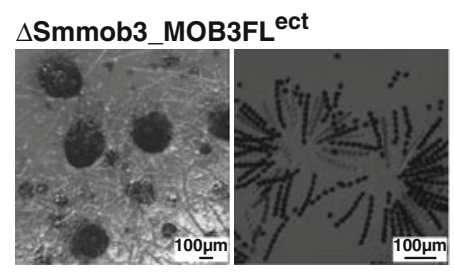

$\Delta$ Smmob3_MOB3N $\mathrm{N}^{\mathrm{ect}}$

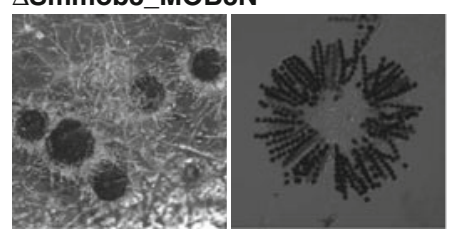

$\Delta$ Smmob3_MOB3C ${ }^{\text {ect }}$

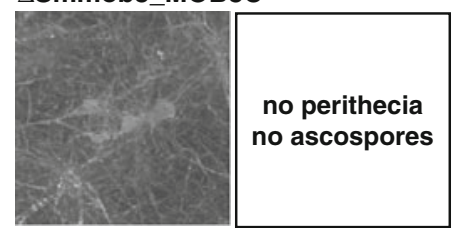

Fig. 4 Complementation analysis in S. macrospora. a Schematic representation of plasmids used for complementation analysis. Plasmids pMob3FL, pMob3N, and pMob3C contain full-length, C-terminal truncated and N-terminal truncated versions of Smmob3 under the control of the endogenous putative Smmob3 promoter region ( $S . m .5^{\prime}$ utr). All plasmids contain the nourseothricin-resistance marker (nat) for selection of transformants. b Investigation of fruiting body and ascospore formation of transformants $\triangle$ Smmob3_MOB3-

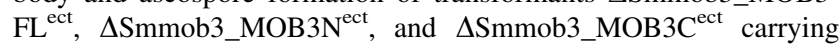
ectopically integrated plasmids pMob3FL, pMob3N, and pMob3C after 10 days of growth on SWG with the digital microscope. Scale bars represent $100 \mu \mathrm{m}$

length Smmob3 (pMob3FL) complemented the sterile phenotype of $\Delta$ Smmob3. Interestingly, the $\mathrm{N}$-terminus of SmMOB3 containing the conserved mob domain (pMob3N), also fully complemented the developmental defect of $\Delta$ Smmob3, while the C-terminus of SmMOB3 alone (pMob3C) did not complement the defect. Previously, we showed that the pro11 mutant was partially complemented with a mouse striatin cDNA (Pöggeler and Kück 2004), so we tested whether the mouse phocein cDNA complemented the $\Delta$ Smmob3 strain. However, no complementation of sexual and/or vegetative growth defects was observed (data not shown). Finally, we analyzed the impact of Smmob3 overexpression on $\Delta$ Smmob3 
and wt. Transformation of plasmid pMob3oex, carrying the Smmob3 gene under control of the strong A. nidulans gpd promoter and $\operatorname{trp} C$ terminator, restored the sterile phenotype of $\Delta \mathrm{Smmob3}$. However, no irregularities in growth behaviour or sexual reproduction were seen between wt and transformants overexpressing Smmob3 (data not shown).

$\Delta$ Smmob3 and pro11 mutant strains are impaired in hyphal fusion

S. macrospora is a homothallic fungus that produces selffertile perithecia. Thus, distinguishing between self-fertile and hybrid perithecia in crosses of wt strains is difficult. To circumvent this problem, spore-color mutants or sterile mutants can be used in crosses. A cross between wt and spore-color mutant results in hybrid perithecia in the contact zone, with asci containing four black wt spores and four colored spores. When two sterile strains are used in a cross, complementation of genetic defects results in the formation of fertile perithecia only in the contact zone of two mutant mycelia, all of which are hybrid perithecia.

Attempts to generate a pro11/ $\Delta$ Smmob3 double mutant strain by crossing the two sterile mutants failed, because recombinant perithecia were never generated. To analyze this apparent fusion defect of pro11 and $\Delta$ Smmob3 in more detail, we counted the number of hybrid perithecia in crosses between wt and mutant strains (Fig. 5a). The wt $\times$ fus-1 spore color mutant crossses $(n=4)$ resulted in 105 $( \pm 29)$ of $1269( \pm 111)$ perithecia with recombinant asci (corresponding to $8 \%$ of all perithecia in the $1-\mathrm{cm}$ wide crossing zone). Decreased numbers of perithecia in the crossing fronts were seen between pro11 $\times$ fus- 1 $(649 \pm 37)$, and $\Delta$ Smmob3 $\times$ fus- $1 \quad(307 \pm 86)$. As expected, the sterility of one partner in these crosses resulted in an increased number of recombinant perithecia ( $21 \%$ in pro1 $1 \times$ fus- 1 , and $24 \%$ in $\Delta$ Smmob3 $\times$ fus- 1 ) compared to the wt $\times$ fus- 1 cross.

No perithecia were generated in the cross between $\Delta$ Smmob3:fus-1 and pro11. To confirm this result, we analyzed fruiting body formation on $80 \Delta$ Smmob3:fus$1 \times$ pro11 crossing plates, but detected no hybrid perithecia, even after prolonged incubation. To exclude the possibility that the fusion defect was caused by mutant sterility, we performed crosses of mutant pro11:r2 or $\Delta$ Smmob3:fus-1 with the sterile mutant pro1, which is deleted for the prol gene coding for a $\mathrm{C}_{6}$ zinc finger transcription factor (Masloff et al. 1999). These crosses gave hybrid perithecia in the crossing front of 63\% (67 out of 105) for pro11:r2 x pro1, and 67\% (6 out of 9) for $\Delta$ Smmob3:fus- $1 \times$ pro1 confirming that the cell fusion defect observed between pro1 1 and $\Delta$ Smmob3 is specific for mutations in these two genes. Light microscopic investigation of vegetative hyphae of the wt and $\Delta \mathrm{Smmob3}$ showed that the mutant was clearly defected in hyphal selffusion (Fig. 5b). While wt strains display several hyphal fusion events and also a few sites of contact without fusion, $\Delta$ Smmob3 exhibits many points of contact, but no evidence of fusion. In most cases hyphae of $\Delta$ Smmob3 grew side by side and seem to form hyphal bundles (Fig. 5b, bottom right).

Downregulation of Smmob3 in pro11 and prol1 in $\Delta$ Smmob3 by RNAi resulted in synthetic defects

We could not generate a pro11/ $\Delta$ Smmob3 double mutant strain by crossing, so we downregulated the Smmob3 gene in the pro11 mutant, and the proll gene in the $\Delta$ Smmob3 mutant by transforming the RNAi vectors pMob3si or pPro11si into the appropriate mutant strains. To ensure that silencing vectors downregulated transcriptional expression, both were also transformed into the wt. The morphological phenotypes of the resulting strains wt_trpC-MOB3si ${ }^{\text {ect }}$ and wt_trpC-PRO11si ${ }^{\text {ect }}$ mimicked the $\Delta$ Smmob3 and pro11 mutant phenotypes. Thus, suggesting that the phenotype of the disrupted $\Delta$ Smmob3 strain represents a complete deletion phenotype.

Similar to the corresponding single mutant, wt RNAi transformants developed only pigmented protoperithecia but no perithecia and ascospores (Fig. 6a). Quantitative real-time PCR verified that transcriptional expression of prol1 or Smmob3 was significantly downregulated in the tested RNAi strains (Fig. 6b).

Mutant strains carrying an additional silencing construct (pro11_trpC-MOB3si ${ }^{\text {ect }}$ and $\Delta$ Smmob3_trpC-PRO11 si ${ }^{\text {ect }}$ ) displayed more severe phenotypes. While pro11_trpCMOB3 $\mathrm{si}^{\text {ect }}$ transformants were no longer able to produce pigmented protoperithecia, downregulation of proll in the $\Delta$ Smmob3 mutant led to an even earlier block of development. $\Delta$ Smmob3_trpC-PRO11si ${ }^{\text {ect }}$ transformants only very rarely produced ascogonia and were no longer able to develop protoperithecia (Fig. 6a).

\section{Discussion}

Fruiting body development in the ascomycete $S$. macrospora is a complex cellular differentiation process controlled by many developmental genes (Kück et al. 2009; Nowrousian et al. 2010). Previously, we showed that the proll gene of $S$. macrospora encodes a protein of the striatin protein family that is essential for fruiting body development (Pöggeler and Kück 2004). A two-hybrid screen with striatin of Rattus norvegicus as bait identified phocein as a striatin interaction partner. Phocein is a member of the highly conserved Mob1/phocein (PF03637) 
Fig. 5 Analysis of hyphal fusion. a The number of perithecia per crossing front of the crosses wt $\times$ fus- 1 , pro1 $1 \times$ fus- $1, \Delta$ Smmob3 $\times$ fus- 1 and $\Delta$ Smmob3/fus- $1 \times$ pro11 was determined (white columns; numbers given above). All perithecia of the crossing front were opened and the number of perithecia containing recombinant asci was defined and converted in percentage (grey columns; numbers given above). Error bars as indicated. To exemplify the experimental approach, a typical crossing plate (in this case a cross between wt and fus-1) is shown. The $1 \mathrm{~cm}$ crossing front (cf, indicated by black lines) was cut from the plate to count and analyze the perithecia. b Subperipheral regions $5-10 \mathrm{~mm}$ from the colony edges of $S$. macrospora wt and $\Delta$ Smmob3 strains were analyzed by DIC microscopy after $48 \mathrm{~h}$ of incubation on MMS minimal medium. Hyphal fusion events are indicated by circles, hyphal contacts without fusion are marked by stars. All hyphal fusions were verified by monitoring cytoplasmic flow through the fusion contact zones. Bar represents $25 \mu \mathrm{m}$
A
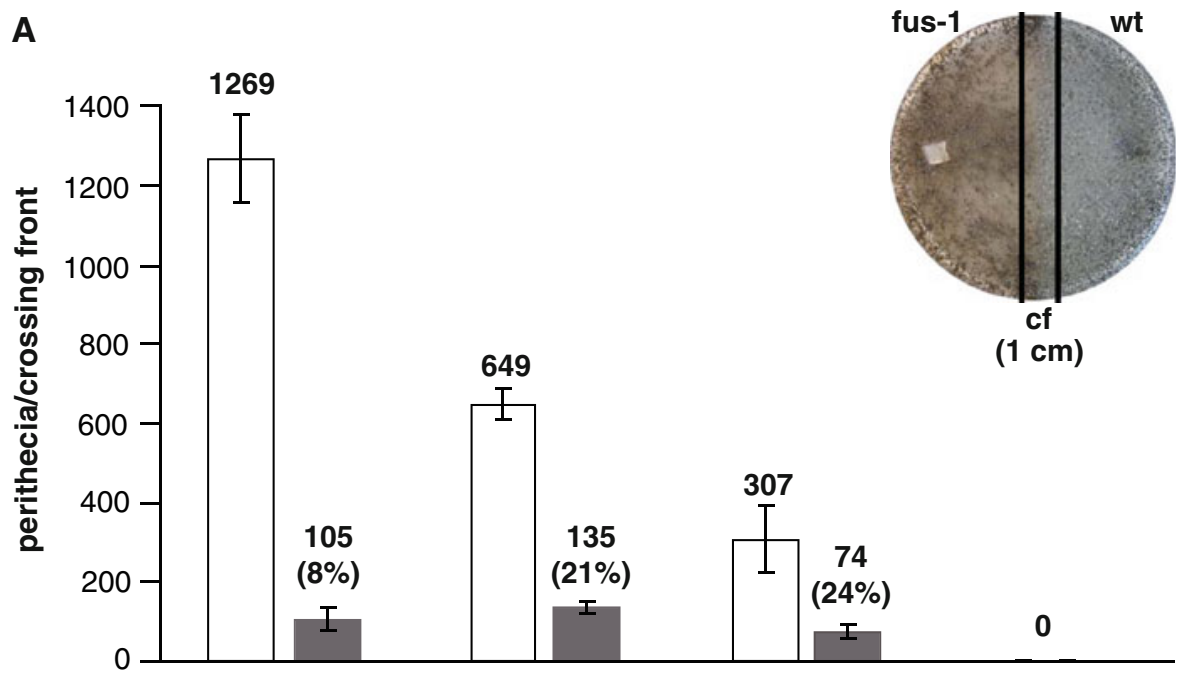

wt $x$ fus- 1

B

wt

$\Delta$ Smmob3
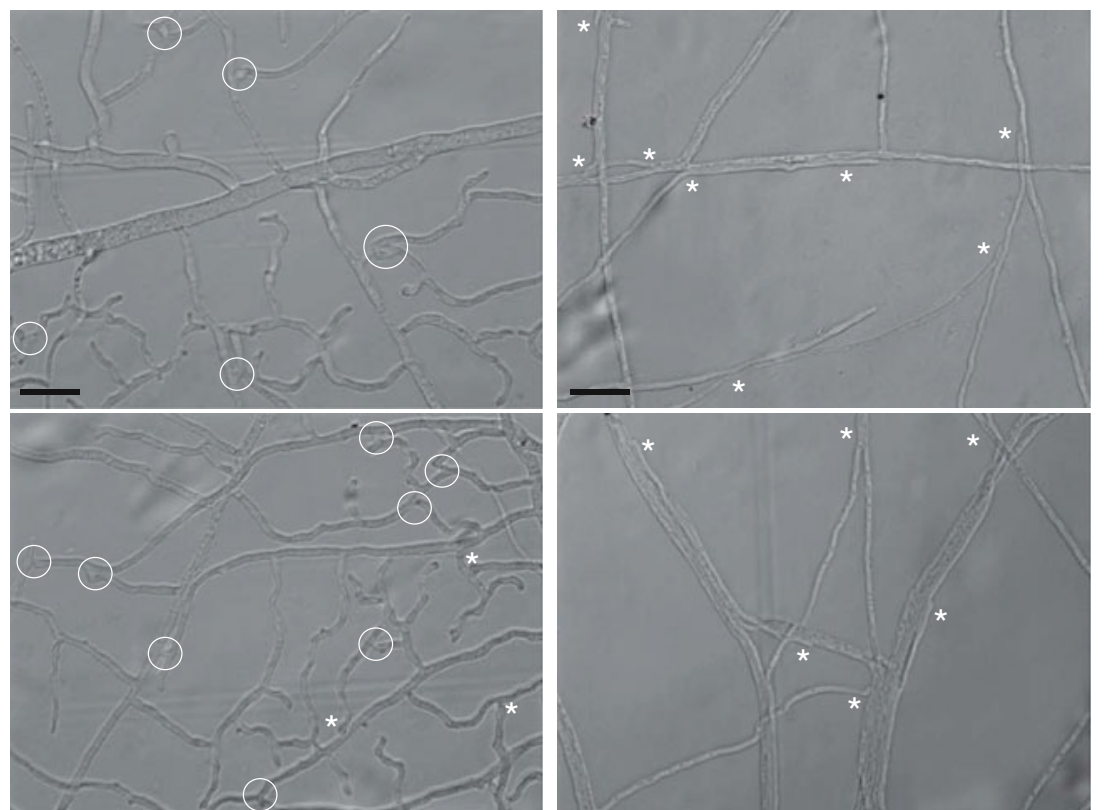

family, which possess a conserved 180-200-aa core mob domain with an $\alpha$-helical structure (Mrkobrada et al. 2006; Vitulo et al. 2007). Proteins of this family participate in a variety of cellular processes, mainly by acting as kinaseactivating subunits (Luca et al. 2001; Mah et al. 2001). Phocein belongs to the Mob3-like group, the most divergent clade of the five different mob domain classes, and is called Mob3 (Vitulo et al. 2007).

As expected, the highest degree of aa identity to animal Mob3 proteins in SmMOB3 and MOB3 proteins from other filamentous fungi is in the 180-200-aa mob domain. According to the consensus sequence of mob domain proteins, SmMOB3 is clearly classified as a Mob3-like protein (Vitulo et al. 2007). Similar to their mammalian counterparts, fungal MOB3 proteins contain mob domain sequence stretches that are highly similar to the clathrin adaptor complexes small chain signature of the $\sigma$ subunits and to a SH3-binding motif of the PxxDY type (Baillat et al. 2001). Both sequence motifs are common to proteins that act in endocytosis. Small $\sigma$ subunits are suggested to stabilize the adaptor (AP) complexes, which are key factors for membrane sorting during endocytosis (Collins et al. 2002). One major interaction partner of the mammalian AP-2 complex is Eps15, which was first discovered as a substrate of the epidermal growth factor receptor tyrosine kinase activity (Benmerah et al. 1995; Fazioli et al. 1993), 

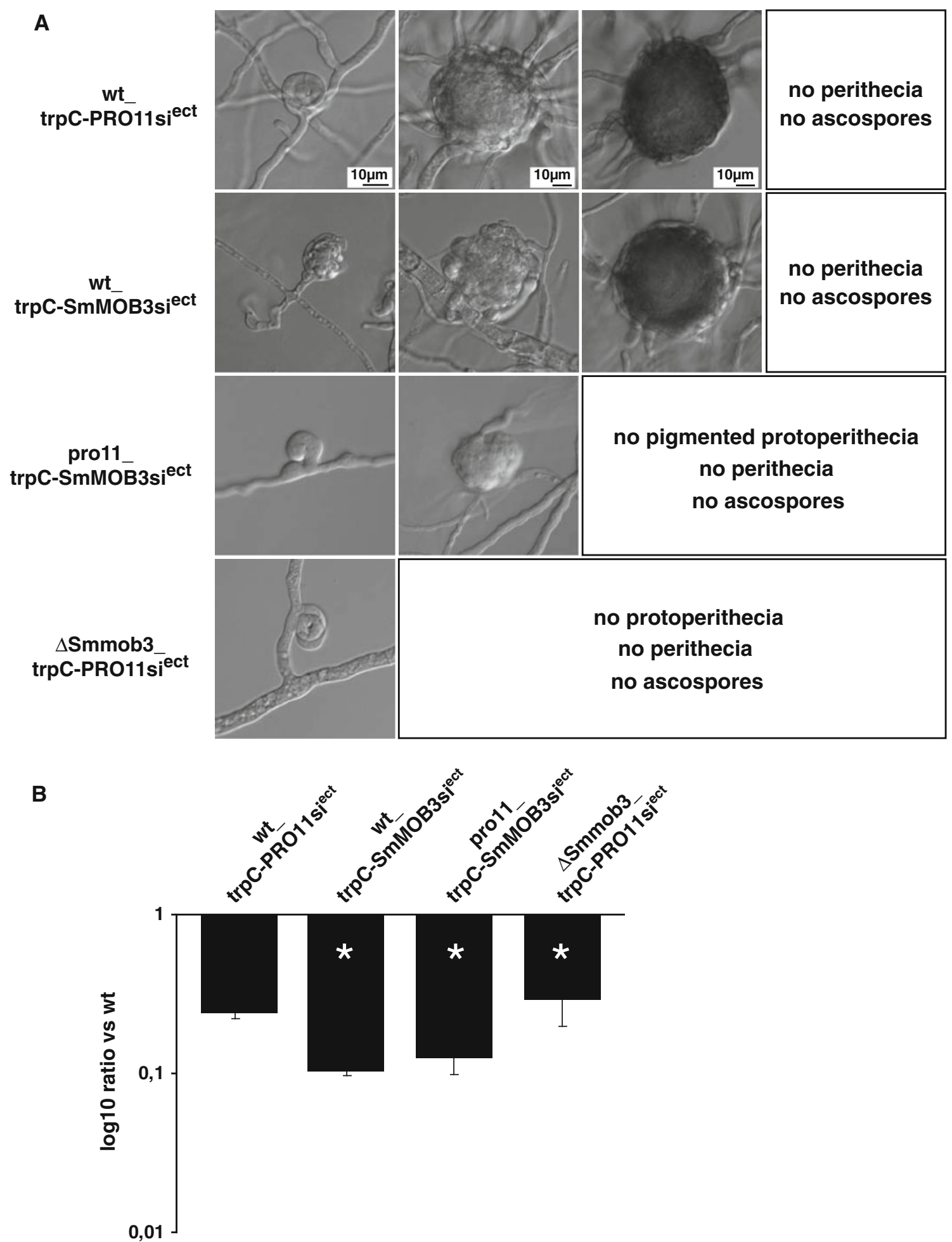

Fig. 6 Downregulation of proll and Smmob3 by RNAi. a RNAi transformants wt_trpC-PRO11 $\mathrm{si}^{\text {ect }}$, wt_trpC-MOB3 $\mathrm{si}^{\text {ect }}$, pro11_trpCMOB3si ${ }^{\text {ect }}$, and $\Delta$ Smmob3_trpC-PRO11si ${ }^{\text {ect }}$ were analyzed for the formation of sexual structures under the microscope. Scale bars represent $10 \mu \mathrm{m}$. b Quantitative real-time PCR of RNAi transformants. Expression of the proll and Smmob3 genes in the RNAi transformants is compared to the wt $(\log 10$ ratio vs. wt). The given values represent mean expression ratios of at least two independent biological samples, each done in triplicates. Asterisks indicate significance calculated according to REST (Pfaffl et al. 2002). Standard deviations as indicated 
but later also shown to interact directly with phocein and NDPK (Baillat et al. 2002). Eps15 genetically and biochemically interacts with dynamin, a GTPase that is crucial for the fission of clathrin-coated vesicles from the plasma membrane, and in other steps of vesicular trafficking (McNiven et al. 2000; Salcini et al. 2001). The SH3binding domain of the $R$. norvegicus Mob3 is a noncanonical PxxDY motif, that was initially identified as a binding motif of the Eps8 SH3-domain (Mongiovi et al. 1999). The variable aa in this motif in SmMOB3, other fungal homologues, and $R$. norvegicus Mob3 are alanine and isoleucine. However, in fungal MOB3 proteins, the conserved proline of the PxxDY motif is replaced by cysteine. Mongiovi et al. (1999) showed that the aspartate and tyrosine residues are essential for SH3-domain binding, while proline contributes only to binding specificity. Therefore, the cysteine residue of the SH3-binding motif of fungal MOB3 proteins conceivably contributes to bindingspecificity to a putative $\mathrm{SH} 3$-domain protein with a unique function in filamentous ascomycetes. The in silico analysis of the SmMOB3 protein suggests a role in clathrindependent endocytosis, which was also proposed for mammalian Mob3 proteins (Baillat et al. 2002); however, the FM4-64 uptake assay revealed no indications of an impaired endocytosis in the $S$. macrospora mutant strain.

With the exception of $S$. cerevisiae Mob1p, and MOB2A and MOB2B in N. crassa, the only Mob proteins described to date are approximately 210-240 aa residues in length. The $S$. cerevisiae Mob1p has an additional 78-residue N-terminal extension that is functionally important, but not conserved in other Mob proteins. X-ray crystal structure analysis showed that the N-terminus of Mob1p interacts with the mob core domain and might be necessary for homodimerization (Mrkobrada et al. 2006). SmMOB3 and homologues of other filamentous ascomycetes have $\mathrm{N}$-terminal extensions of approximately 50 aa, and C-terminal extensions of approximately 400 aa that are not present in any animal Mob3 proteins. These additional Nand C-terminal sequences contain highly conserved domains specific to fungal MOB3 proteins. However, the $\mathrm{N}$-terminal region of SmMOB3 (aa 1-264), including the $\mathrm{N}$-terminal extension and the conserved mob domain, appears to be functionally important, since it is able to fully complement developmental defects of the $S$. macrospora $\Delta$ Smmob3 mutant. From our analysis it is not clear whether the Mob domain alone or only together with the $\mathrm{N}$-terminal extension is sufficient for function. However, the N-terminal extension (aa 1-50) alone is not able to complement the defect (data not shown). Furthermore, the exact function of the $\mathrm{C}$-terminus remains elusive.

The $\Delta$ Smmob3 strain has a sterile phenotype. Sexual differentiation is arrested at the stage of protoperithecium formation and strongly resembles the pro11 mutant phenotype, which is also capable of only protoperithecium formation (Pöggeler and Kück 2004). The recently described phenotype of a $N$. crassa $\Delta m o b-3$ knockout strain (Maerz et al. 2009) coincides with our observations. The $\Delta m o b-3$ strain showed an approximately 30-fold reduction in the number of the produced protoperithecia, which were smaller and less developed than in the wt. In metazoans, the first loss-of-function phocein mutant was described only recently in D. melanogaster (Schulte et al. 2010). The D. melanogaster DMob4 is essential for viability, because homozygous null alleles are larval lethal. Schulte et al. (2010) demonstrated a prominent role for DMob4 in neuronal function, especially in regulating axonal transport, membrane excitability, and of microtubule network organization. Rescue experiments of the $D$. melanogaster DMob4 mutant, using the human DMob4 homologue revealed a function conserved across evolution. However, our attempts to complement the S. macrospora defects with a mouse phocein cDNA failed. This may be due to the low level of homology between fungal and mammalian mob domains $(35 \%)$, while human phocein and DMob4 of D. melanogaster share $80 \%$ identity (Schulte et al. 2010). Alternatively, the additional fungal specific regions have important although currently undefined functions or the mammalian protein is not properly folded in S. macrospora.

In filamentous ascomycetes such as $N$. crassa and $S$. macrospora, homologues of all components of the mammalian STRIPAK complex are present, some of them regulating hyphal fusion and multicellular differentiation during sexual development. In our study, both the pro11 and $\Delta$ Smmob3 strain were defective in hyphal fusion. In $N$. crassa, ham-2 encodes a putative transmembrane protein with similarity to mammalian STRIP1 and STRIP2 proteins. The ham-2 mutant fails to undergo germling and hyphal fusion (Xiang et al. 2002). PRO22, the homologous gene product of $S$. macrospora, also contributes to hyphal fusion events and the corresponding mutant fails to develop mature fruiting bodies and displays a defect in ascogonial septum formation (Bloemendal et al. 2010; Rech et al. 2007). Mutation of the $N$. crassa ham-4, encoding a forkhead-associated (FHA) domain protein similar to SLMAP of STRIPAK, results in a block in vegetative hyphal fusion (Simonin et al. 2010). A relationship exists between the regulation of hyphal fusion and sexual differentiation in filamentous fungi since fusion mutants are often also affected in aspects of sexual development (Bowman et al. 2006; Fleissner et al. 2005, 2009; Li et al. 2005; Maerz et al. 2008, 2009; Read et al. 2010; Rech et al. 2007; Wei et al. 2003; Xiang et al. 2002).

Crosses between pro11 and $\Delta$ Smmob3 resulted in no perithecia or ascospores. This means that these two mutations cannot complement each other. Both proteins seem to 
be essential for hyphal fusion and, therefore, the two mutants are not able to form a heterokaryon and thus remain sterile. Moreover, downregulation of Smmob3 in pro11 and proll in $\Delta$ Smmob3 by RNAi resulted in synthetic defects. Our data suggest that PRO11 and SmMOB3 act together in a pathway controlling cell fusion and sexual differentiation that may also contain other proteins of the mammalian STRIPAK complex and associated MAP kinase signaling pathways. The pleiotropic function observed for striatin-based complexes led Benoist et al. (2006) to speculate that striatin complexes may function as locally assembled signalosomes that spatially and temporally coordinate distinct transduction pathways. Further indepth analysis of the interacting proteins will be required to confirm this hypothesis and to define the underlying signaling pathways. Filamentous fungi are emerging as interesting models for this analysis.

Acknowledgments We thank Regina Ricke and Silke Nimtz for excellent technical assistance and Sascha Menniger for the help with some experiments. We are indebted to Prof. Dr. Heidi Hahn for the gift of mouse cDNA. This work was funded by grants from the Deutsche Forschungsgemeinschaft to S.P. (PO532/4-1).

Open Access This article is distributed under the terms of the Creative Commons Attribution Noncommercial License which permits any noncommercial use, distribution, and reproduction in any medium, provided the original author(s) and source are credited.

\section{References}

Al Dabbous MS, Roca MG, Stout A, Huang IC, Read ND, Free SJ (2010) The ham-5, rcm-1 and $r c o-1$ genes regulate hyphal fusion in Neurospora crassa. Microbiology 156:2621-2629

Altschul SF, Madden TL, Schaffer AA, Zhang J, Zhang Z, Miller W, Lipman DJ (1997) Gapped BLAST and PSI-BLAST: a new generation of protein database search programs. Nucl Acids Res 25:3389-3402

Baillat G, Gaillard S, Castets F, Monneron A (2002) Interactions of phocein with nucleoside-diphosphate kinase, Eps15, and Dynamin I. J Biol Chem 277:18961-18966

Baillat G, Moqrich A, Castets F, Baude A, Bailly Y, Benmerah A, Monneron A (2001) Molecular cloning and characterization of phocein, a protein found from the Golgi complex to dendritic spines. Mol Biol Cell 12:663-673

Becker DM, Lundblad V (2001) Introduction of DNA into yeast cells. Curr Protoc Mol Biol 13:13-17

Benmerah A, Gagnon J, Begue B, Megarbane B, Dautry-Varsat A, Cerf-Bensussan N (1995) The tyrosine kinase substrate eps15 is constitutively associated with the plasma membrane adaptor AP2. J Cell Biol 131:1831-1838

Benoist M, Baude A, Tasmadjian A, Dargent B, Kessler JP, Castets F (2008) Distribution of zinedin in the rat brain. J Neurochem 106:969-977

Benoist M, Gaillard S, Castets F (2006) The striatin family: a new signaling platform in dendritic spines. J Physiol Paris 99:146-153

Bloemendal S, Lord KM, Rech C, Hoff B, Engh I, Read ND, Kück U (2010) A mutant defective in sexual development produces aseptate ascogonia. Eukaryotic Cell. doi:10.1128/ec.00186-10
Blom N, Gammeltoft S, Brunak S (1999) Sequence and structurebased prediction of eukaryotic protein phosphorylation sites. J Mol Biol 294:1351-1362

Bowman SM, Piwowar A, Al Dabbous M, Vierula J, Free SJ (2006) Mutational analysis of the glycosylphosphatidylinositol (GPI) anchor pathway demonstrates that GPI-anchored proteins are required for cell wall biogenesis and normal hyphal growth in Neurospora crassa. Eukaryot Cell 5:587-600

Carroll AM, Sweigard JA, Valent B (1994) Improved vectors for selecting resistance to hygromycin. Fungal Genet Newslett 41:22

Castets F, Bartoli M, Barnier JV, Baillat G, Salin P, Moqrich A, Bourgeois JP, Denizot F, Rougon G, Calothy G, Monneron A (1996) A novel calmodulin-binding protein, belonging to the WD-repeat family, is localized in dendrites of a subset of CNS neurons. J Cell Biol 134:1051-1062

Chen HW, Marinissen MJ, Oh SW, Chen X, Melnick M, Perrimon N, Gutkind JS, Hou SX (2002) CKA, a novel multidomain protein, regulates the JUN N-terminal kinase signal transduction pathway in Drosophila. Mol Cell Biol 22:1792-1803

Chow A, Hao Y, Yang X (2010) Molecular characterization of human homologs of yeast MOB1. Int J Cancer 126:2079-2089

Christianson TW, Sikorski RS, Dante M, Shero JH, Hieter P (1992) Multifunctional yeast high-copy-number shuttle vectors. Gene 110:119-122

Collins BM, McCoy AJ, Kent HM, Evans PR, Owen DJ (2002) Molecular architecture and functional model of the endocytic AP2 complex. Cell 109:523-535

Colot HV, Park G, Turner GE, Ringelberg C, Crew CM, Litvinkova L, Weiss RL, Borkovich KA, Dunlap JC (2006) A highthroughput gene knockout procedure for Neurospora reveals functions for multiple transcription factors. Proc Natl Acad Sci USA 103:10352-10357

Elleuche S, Pöggeler S (2008) Visualization of peroxisomes via SKLtagged DsRed protein in Sordaria macrospora. Fungal Genet Rep 55:9-12

Elleuche S, Pöggeler S (2009) Beta-carbonic anhydrases play a role in fruiting body development and ascospore germination in the filamentous fungus Sordaria macrospora. PLoS One 4:e5177

Esser K (1982) Cryptogams-Cyanaobacteria, Fungi, Algae and Lichens. Cambridge University Press, London

Fazioli F, Minichiello L, Matoskova B, Wong WT, Di Fiore PP (1993) eps15, a novel tyrosine kinase substrate, exhibits transforming activity. Mol Cell Biol 13:5814-5828

Fischer-Parton S, Parton RM, Hickey PC, Dijksterhuis J, Atkinson HA, Read ND (2000) Confocal microscopy of FM4-64 as a tool for analysing endocytosis and vesicle trafficking in living fungal hyphae. J Microsc 198:246-259

Fleissner A, Diamond S, Glass NL (2009) The Saccharomyces cerevisiae PRM1 homolog in Neurospora crassa is involved in vegetative and sexual cell fusion events but also has postfertilization functions. Genetics 181:497-510

Fleissner A, Sarkar S, Jacobson DJ, Roca MG, Read ND, Glass NL (2005) The so locus is required for vegetative cell fusion and postfertilization events in Neurospora crassa. Eukaryot Cell 4:920-930

Gaillard S, Bailly Y, Benoist M, Rakitina T, Kessler JP, FronzaroliMolinieres L, Dargent B, Castets F (2006) Targeting of proteins of the striatin family to dendritic spines: role of the coiled-coil domain. Traffic 7:74-84

Gasteiger E, Hoogland C, Gattiker A, Duvaud S, Wilkins MR, Appel RD, Bairoch A (2005) Protein identification and analysis tools on the ExPASy Server. In: Walker JM (ed) The Proteomics Handbook. Humana Press, New York, pp 571-607

Goudreault M, D'Ambrosio LM, Kean MJ, Mullin M, Larsen BG, Sanchez A, Chaudhry S, Chen GI, Sicheri F, Nesvizhskii AI, Aebersold R, Raught B, Gingras AC (2009) A PP2A phosphatase 
high-density interaction network identifies a novel striatininteracting phosphatase and kinase complex linked to the cerebral cavernous malformation 3 (CCM3) protein. Mol Cell Proteomics 8:157-171

Huang X, Miller M (1991) A time-efficient, linear-space local similarity algorithm. Adv Appl Math 12:337-357

James P, Halladay J, Craig EA (1996) Genomic libraries and a host strain designed for highly efficient two-hybrid selection in yeast. Genetics 144:1236-1425

Janus D, Hoff B, Hofmann E, Kück U (2007) An efficient fungal RNA-silencing system using the DsRed reporter gene. Appl Environ Microbiol 73:962-970

Kachidian P, Vuillet J, Bartoli M, Castets F, Nieoullon A, KerkerianLe Goff L (1998) Relationships between striatin-containing neurons and cortical or thalamic afferent fibres in the rat striatum. An ultrastructural study by dual labelling. Neuroscience 85:111-122

Klix V, Nowrousian M, Ringelberg C, Loros JJ, Dunlap JC, Pöggeler S (2010) Functional characterization of MAT1-1-specific mating-type genes in the homothallic ascomycete Sordaria macrospora provides new insights into essential and non-essential sexual regulators. Eukaryot Cell (in press)

Kück U, Pöggeler S, Nowrousian M, Nolting N, Engh I (2009) Sordaria macrospora, a model system for fungal development. In: Anke T, Weber D (eds) THE MYCOTA XV, physiology and genetics: selected basic and applied aspects (The Mycota). Springer, Heidelberg, pp 17-39

Li D, Bobrowicz P, Wilkinson HH, Ebbole DJ (2005) A mitogenactivated protein kinase pathway essential for mating and contributing to vegetative growth in Neurospora crassa. Genetics 170:1091-1104

Luca FC, Mody M, Kurischko C, Roof DM, Giddings TH, Winey M (2001) Saccharomyces cerevisiae Moblp is required for cytokinesis and mitotic exit. Mol Cell Biol 21:6972-6983

Luca FC, Winey M (1998) MOB1, an essential yeast gene required for completion of mitosis and maintenance of ploidy. Mol Biol Cell 9:29-46

Ma H-L, Peng Y-L, Gong L, Liu W-B, Sun S, Liu J, Zheng C-B, Fu H, Yuan D, Zhao J, Chen P-C, Xie S-s, Zeng X-M, Xiao Y-M, Liu Y, Li DW-C (2009) The Goldfish SG2NA gene encodes two $\alpha$-type regulatory subunits for PP-2A and displays distinct developmental expression pattern. Gene Regulat Syst Biol 2009:115

Maerz S, Dettmann A, Ziv C, Liu Y, Valerius O, Yarden O, Seiler S (2009) Two NDR kinase-MOB complexes function as distinct modules during septum formation and tip extension in Neurospora crassa. Mol Microbiol 74:707-723

Maerz S, Ziv C, Vogt N, Helmstaedt K, Cohen N, Gorovits R, Yarden O, Seiler S (2008) The nuclear Dbf2-related kinase COT1 and the mitogen-activated protein kinases MAK1 and MAK2 genetically interact to regulate filamentous growth, hyphal fusion and sexual development in Neurospora crassa. Genetics 179:1313-1325

Mah AS, Jang J, Deshaies RJ (2001) Protein kinase Cdc15 activates the Dbf2-Mob1 kinase complex. Proc Natl Acad Sci USA 98:7325-7330

Masloff S, Pöggeler S, Kück U (1999) The prol(+) gene from Sordaria macrospora encodes a C6 zinc finger transcription factor required for fruiting body development. Genetics 152:191-199

McNiven MA, Cao H, Pitts KR, Yoon Y (2000) The dynamin family of mechanoenzymes: pinching in new places. Trends Biochem Sci 25:115-120

Mongiovi AM, Romano PR, Panni S, Mendoza M, Wong WT, Musacchio A, Cesareni G, Di Fiore PP (1999) A novel peptideSH3 interaction. EMBO J 18:5300-5309
Moreno CS, Lane WS, Pallas DC (2001) A mammalian homolog of yeast $M O B 1$ is both a member and a putative substrate of striatin family-protein phosphatase $2 \mathrm{~A}$ complexes. J Biol Chem 276:24253-24260

Mrkobrada S, Boucher L, Ceccarelli DF, Tyers M, Sicheri F (2006) Structural and functional analysis of Saccharomyces cerevisiae Mob1. J Mol Biol 362:430-440

Nolting N, Pöggeler S (2006a) A MADS box protein interacts with a mating-type protein and is required for fruiting body development in the homothallic ascomycete Sordaria macrospora. Eukaryot Cell 5:1043-1056

Nolting N, Pöggeler S (2006b) A STE12 homologue of the homothallic ascomycete Sordaria macrospora interacts with the MADS box protein MCM1 and is required for ascosporogenesis. Mol Microbiol 62:853-868

Nowrousian M, Cebula P (2005) The gene for a lectin-like protein is transcriptionally activated during sexual development, but is not essential for fruiting body formation in the filamentous fungus Sordaria macrospora. BMC Microbiol 5:64

Nowrousian M, Masloff S, Pöggeler S, Kück U (1999) Cell differentiation during sexual development of the fungus Sordaria macrospora requires ATP citrate lyase activity. Mol Cell Biol 19:450-460

Nowrousian M, Stajich JE, Chu M, Engh I, Espagne E, Halliday K, Kamerewerd J, Kempken F, Knab B, Kuo HC, Osiewacz HD, Pöggeler S, Read ND, Seiler S, Smith KM, Zickler D, Kück U, Freitag M (2010) De novo assembly of a $40 \mathrm{Mb}$ eukaryotic genome from short sequence reads: Sordaria macrospora, a model organism for fungal morphogenesis. PLoS Genet 6:e1000891

Nowrousian M, Würtz C, Pöggeler S, Kück U (2004) Comparative sequence analysis of Sordaria macrospora and Neurospora crassa as a means to improve genome annotation. Fungal Genet Biol 41:285-292

Pfaffl MW, Horgan GW, Dempfle L (2002) Relative expression software tool (REST) for group-wise comparison and statistical analysis of relative expression results in real-time PCR. Nucl Acids Res 30:e36

Pöggeler S (1997) Sequence characteristics within nuclear genes from Sordaria macrospora. Fungal Genet Newslett 41:41-44

Pöggeler S, Kück U (2004) A WD40 repeat protein regulates fungal cell differentiation and can be replaced functionally by the mammalian homologue striatin. Eukaryot Cell 3:232-240

Pöggeler S, Kück U (2006) Highly efficient generation of signal transduction knockout mutants using a fungal strain deficient in the mammalian $k u 70$ ortholog. Gene 378:1-10

Pöggeler S, Masloff S, Hoff B, Mayrhofer S, Kück U (2003) Versatile EGFP reporter plasmids for cellular localization of recombinant gene products in filamentous fungi. Curr Genet 43:54-61

Pöggeler S, Nowrousian M, Jacobsen S, Kück U (1997a) An efficient procedure to isolate fungal genes from an indexed cosmid library. J Microbiol Method 29:49-61

Pöggeler S, Risch S, Kück U, Osiewacz HD (1997b) Mating-type genes from the homothallic fungus Sordaria macrospora are functionally expressed in a heterothallic ascomycete. Genetics 147:567-580

Ponchon L, Dumas C, Fesquet D, Padilla A (2004) Resonance assignments and topology of the $15 \mathrm{~N}, 13 \mathrm{C}$ labelled $23 \mathrm{kDa}$ core domain of xenopus Mob1. J Biomol NMR 28:299-300

Read ND, Fleißner A, Glass NL (2010) Hyphal Fusion. In: Borkovich KA, Ebbole DJ (eds) Cellular and molecular biology of filamentous fungi. ASM Press, Washington, pp 260-273

Rech C, Engh I, Kück U (2007) Detection of hyphal fusion in filamentous fungi using differently fluorescence-labeled histones. Curr Genet 52:259-266 
Reese MG (2001) Application of a time-delay neural network to promoter annotation in the Drosophila melanogaster genome. Comput Chem 26:51-56

Salcini AE, Hilliard MA, Croce A, Arbucci S, Luzzi P, Tacchetti C, Daniell L, De Camilli P, Pelicci PG, Di Fiore PP, Bazzicalupo P (2001) The Eps15 C. elegans homologue EHS-1 is implicated in synaptic vesicle recycling. Nat Cell Biol 3:755-760

Sambrook J, Fritsch E, Maniatis T (2001) Molecular cloning: a laboratory manual, 2nd edn. Cold Spring Harbor Laboratory Press, Cold Spring Habor

Schulte J, Sepp KJ, Jorquera RA, Wu C, Song Y, Hong P, Littleton JT (2010) DMob4/Phocein regulates synapse formation, axonal transport, and microtubule organization. J Neurosci 30:5189-5203

Shim WB, Sagaram US, Choi YE, So J, Wilkinson HH, Lee YW (2006) FSR1 is essential for virulence and female fertility in Fusarium verticillioides and $F$. graminearum. Mol Plant Microbe Interact 19:725-733

Simonin AR, Rasmussen CG, Yang M, Glass NL (2010) Genes encoding a striatin-like protein (ham-3) and a forkhead associated protein (ham-4) are required for hyphal fusion in Neurospora crassa. Fungal Genet Biol 47:855-868

Song S, Zhang T, Qi W, Zhao W, Xu B, Liu J (1993) Transformation of Escherichia coli with foreign DNA by electroporation. Chin J Biotechnol 9:197-201

Stavridi ES, Harris KG, Huyen Y, Bothos J, Verwoerd PM, Stayrook SE, Pavletich NP, Jeffrey PD, Luca FC (2003) Crystal structure of a human Mob1 protein: toward understanding Mob-regulated cell cycle pathways. Structure 11:1163-1170

Thompson JD, Gibson TJ, Plewniak F, Jeanmougin F, Higgins DG (1997) The CLUSTAL_X windows interface: flexible strategies for multiple sequence alignment aided by quality analysis tools. Nucl Acids Res 25:4876-4882

Trammell MA, Mahoney NM, Agard DA, Vale RD (2008) Mob4 plays a role in spindle focusing in Drosophila S2 cells. J Cell Sci 121:1284-1292

Vitulo N, Vezzi A, Galla G, Citterio S, Marino G, Ruperti B, Zermiani M, Albertini E, Valle G, Barcaccia G (2007) Characterization and evolution of the cell cycle-associated mob domain-containing proteins in eukaryotes. Evol Bioinform Online 3:121-158

Wang CL, Shim WB, Shaw BD (2010) Aspergillus nidulans striatin (StrA) mediates sexual development and localizes to the endoplasmic reticulum. Fungal Genet Biol 47:789-799

Wei H, Requena N, Fischer R (2003) The MAPKK kinase SteC regulates conidiophore morphology and is essential for heterokaryon formation and sexual development in the homothallic fungus Aspergillus nidulans. Mol Microbiol 47:1577-1588

Xiang Q, Rasmussen C, Glass NL (2002) The ham-2 locus, encoding a putative transmembrane protein, is required for hyphal fusion in Neurospora crassa. Genetics 160:169-180 